\title{
Reflective Apprenticeship for Teaching and Learning Mathematical Proof
}

\author{
Daniel L. Reinholz \\ San Diego State University, USA
}

\begin{abstract}
This article explores teacher learning in a graduate-level analysis course for teachers. Drawing from the frameworks of extreme apprenticeship and Peer-Assisted Reflection (PAR), the course created authentic learning experiences for the teachers that served as models that they could use in their own classrooms. This paper describes how the teachers developed across the four dimensions of extreme apprenticeship. While this paper is grounded in mathematics, the extreme apprenticeship and PAR frameworks are cross-disciplinary, and thus there are implications for teaching and learning in all of the STEM disciplines.
\end{abstract}

Keywords: Mathematical analysis, extreme apprenticeship, Peer-Assisted Reflection

\section{Introduction}

Who can be a mathematician? What is mathematics all about? How should mathematics be taught? We tend to answer these questions based on our experiences with our own mathematics teachers: what they looked like, what they asked us to do, and how they taught us. However, this poses a challenge for new teachers who are expected to teach in increasingly innovative ways and address new content standards. How does one teach mathematics in a way that they have seldom experienced?

Prospective teachers generally experience a variety of pedagogies in their mathematics education courses. However, these particular activities often contrast their regular mathematics courses, which are primarily lecture-based. This can cause problems, because prospective teachers have limited opportunities to experience innovative pedagogies as mathematics learners themselves. As such, I argue, it is critical that students have similar learning experiences in their mathematics courses too.

This article focuses on an analysis course for teachers. I take the lens of extreme apprenticeship (Vihavainen, Paksula, \& Luukkainen, 2011), in which teachers are given opportunities to experience the type of learning experiences that they would create for their students. To support their apprenticeship, the students engaged in Peer-Assisted Reflection, or PAR (Reinholz, 2015a), as a way to help them reflect on mathematical proof. This paper addresses the following question:

How were teachers in the course able to use PAR to engage with the four components of extreme apprenticeship?

Teachers in the present study applied their experiences from this course in their own teaching in various ways. Teachers used specific pedagogical strategies (e.g., PAR, team-based learning), content areas (e.g., spacefilling curves, countable sets), and particular activities from class (e.g., iteratively constructing Hilbert curves using whiteboards or construction paper). To address the above question, I focus specifically on three of the

${ }^{1}$ San Diego State University Department of Mathematics \& Statistics 5500 Campanile Drive San Diego, CA 92182-7720 USA, E-mail: daniel.reinholz@ sdsu.edu

Reinholz, D. L. (2017). Reflective apprenticeship for teaching and learning mathematical proof. Journal of Research in STEM Education, 4(1), 68-80. 
five K-12 teachers in the course, because they spontaneously chose to implement PAR in their K-12 teaching. ${ }^{1}$ I focus on PAR, because it was a structured pedagogical practice that the teachers could use in a variety of settings, unlike more specific aspects of the course, such as particular content. Also, I choose to focus on the K-12 teachers to take the lens of in-service teacher development. Graduate Teaching Assistants in the course also applied their experiences from the course in their own teaching, but because of the differences in their setting, an exploration of their work is beyond the scope of this article.

Note, using ideas from the analysis course in K-12 teaching was not an explicit goal of the course, but rather, the students found their learning experiences so worthwhile that they decided to use them in their own teaching. While this paper is grounded in proof and mathematics, both extreme apprenticeship and PAR are interdisciplinary frameworks, and thus the implications of this paper speak to teaching authentic practices in all STEM disciplines.

\section{Background}

The sociocultural turn in mathematics education has placed an increasing emphasis on how students learn through engaging in social practices (e.g., Cobb, Stephan, McClain, \& Gravemeijer, 2011; Lave, 1996; Sfard, 1998). As a result of this turn, there is now rich empirical evidence (e.g., Freeman et al., 2014) for much earlier educational theories that focused on the ideas of learning by doing, or experiential learning (e.g., Dewey, 1933; Kolb, 1984). A key component of experiential learning is reflection: the act of processing an experience, action, or practice to gain further insight into the experience to better inform and guide future actions (Reinholz, 2016). Reflection is seen as a fundamental component of teacher education, to help teachers develop reflective practice (e.g., Averill, Drake, Anderson, \& Anthony, 2016; Reinholz, 2017; Sherin, Jacobs, \& Philipp, 2011).

In the present study, students were supported to reflect through a particular course activity, PeerAssisted Reflection (PAR; Reinholz, 2015a). PAR is a structured peer review process involving the following steps: students work on a draft of a problem, exchange feedback with a peer, and then revise before turning in their solutions. PAR helps students develop stronger self-assessment skills as they develop objective lenses from critiquing the work of their peers (Black, Harrison, \& Lee, 2003; Reinholz, 2015b). In this course, teachers used PAR to annotate one another's proofs and provide constructive feedback. Thus, PAR was used to support the learning of proof, a core mathematical practice. PAR is a cross-disciplinary technique, and has also been used in other disciplines such as biology, engineering, and physics (e.g., Reinholz \& Dounas-Frazer, 2016).

To create space for students to annotate each other's work, students completed their proofs using a two-column format. The left column was for formal mathematics and the right column was for annotations. Annotations were used for a variety of purposes. Authors could comment on their thought process, include relevant diagrams and definitions, and express areas of confusion. For peer review, students used annotations to provide feedback to each other. Authors used pencil for their annotations, while reviewers used pen, which allowed these two types of comments to easily be distinguished. See Appendix A for a sample of the written work associated with PAR.

Reflection was seen as a smaller component of a larger educational framework called extreme apprenticeship (Vihavainen et al., 2011). This framework has its roots in cognitive apprenticeship, and focuses on learning through practice. The method is guided by four key principles:

1. Learning by doing. You can only master something by actually practicing it.

2. Continuous feedback. Feedback should be ongoing and bidirectional.

3. No compromise. Seek to attain high levels of understanding.

${ }^{1}$ A fourth in-service teacher later used PAR in their teaching, but this was conveyed in a personal communication, after the course had completed (so no data were collected for this teacher). 
4. Apprentice to mastery. Students eventually become experts in the method.

These four principles were embodied into the PAR process and how it was used in the class. Students engaged in authentic practice of conjecture, peer review, and revision, just as professional mathematicians would. This supported learning by doing. Continuous feedback was implemented by students both giving and receiving feedback from their peers. The idea of no compromise guided how students were to think about proof: high standards of argumentation were required. Students were expected to overcome some of the key issues in learning proof, such as using empirical arguments (e.g., Healy \& Hoyles, 2000; Martin \& Harel, 1989) or misunderstanding the logical necessity of deductive argumentation (Fischbein, 1982). Finally, the presence of the fourth principle, apprentice to mastery, was emergent in students' work. While a goal of the course was to model good pedagogy for students, it was not actually anticipated that students would already begin to use teaching techniques that they experienced as students in their own K-12 teaching. Here, as the teachers used PAR with their students, it signified them coming to the role of masters of the process.

As stated above, PAR was used to help students gain authentic experiences with proof. In particular, the course emphasized the process of proving and the many functions that proof can serve. For instance, proofs in this course were intended to both prove and explain mathematics (De Villiers, 2003; Steiner, 1978). In this way, proofs can actually serve a pedagogical function, teaching others how to "do" mathematics (Hanna, 1990). Above all, proof was understood as a social process. It wasn't just about ascertaining truth, but also communicating ideas under a certain set of social norms (cf. Harel \& Sowder, 2007; Mason, Burton, \& Stacey, 2010). In this way, PAR served a number of roles in this classroom setting: teaching students mathematics, teaching them about proof, and teaching them how to teach mathematics.

\section{Method}

\section{Context and Participants}

The target course, taught by the author, served students in a Master's degree program in mathematics education in the US. These students are referred to as teachers throughout this article, to distinguish them from the students that they were presently teaching or may teach in the future. A total of 13 teachers were in the analysis course, all who consented to participate in the study. There were five in-service teachers, five Graduate Teaching Assistants (GTAs), two prospective teachers who were not yet teaching, and one mathematics graduate student.

The course content was graduate-level analysis, but in contrast to a traditional course, it featured the use of student-centered pedagogies to help the teachers develop mathematical ideas. While the course had a strong emphasis on proof, it also emphasized discovery of mathematics through inquiry, exploration, and creativity. Most class sessions involved students working in teams on mathematics problems in an inquiry-oriented way, summarized with whole-class discussions and team presentations. Teacher exposition was a small component of the course. Team-based learning was used to organize collaborative work (Michaelsen, Parmelee, McMahon, \& Levine, 2008). Team-based learning involves using consistent groups throughout the semester, team-based assignments, and team contracts to establish norms. Students participated in the PAR process each week with a single homework problem.

\section{Data Sources}

There were two primary data sources, corresponding to questions on the first and second midterms in the course. The following questions was taken from the first midterm:

Take an idea from this semester so far and describe how you could use this in your teaching. You may talk about a class you're already teaching, or something you envision yourself teaching in the future. 
On the final, there was the following question about proofs:

Write an essay about what makes a good proof. Obviously it should be mathematically correct, but what else matters? Please address the following questions, using concrete examples when possible:

1. How does your experience with proof in this class compare to your experiences with proof in other classes?

2. What does a "good proof" look like? What information does it provide for a reader?

3. What should you include in an annotation of your own proof, to make it easier for a peer to understand?

4. What type of feedback should you provide to a peer (when annotating their work) to help them create a good proof?

5. What are the implications for the teaching and learning of proof?

Note that neither of these questions (nor the course) actually required students to apply anything they learned to their own teaching. Nevertheless, the teachers began to spontaneously use many ideas from the analysis course in their work with their own students. In the results that follow, I describe how PAR helped students engage in the four principles of extreme apprenticeship.

\section{Results}

The 13 teachers discussed a variety of connections between their learning in the analysis course and their own teaching. They discussed specific pedagogical strategies (e.g., PAR, team-based learning), content areas (e.g., space-filling curves, countable sets), and particular activities from class (e.g., iteratively constructing Hilbert curves using whiteboards or construction paper). Here I focus on three teachers that decided to use PAR from the course in their own teaching (a fourth teacher later used PAR but this happened after data collection was complete, so it is not reported on here). In particular, I use student reflections to show how PAR supported teachers to embody the four principles of extreme apprenticeship, which helped them transfer PAR to their own teaching.

\section{Learning by Doing}

The first principle of extreme apprenticeship is learning by doing. Through PAR, students were actually engaged in the very process of conjecturing, proof writing, and academic peer review that professional mathematicians would practice. Each of the three focal teachers, John, Dana, and Melvin, noted how this authentic practice supported their learning. John drew connections to constructivism, Dana to the process of peer annotation, and Melvin to the proof process, not just a proof itself.

In what follows, John highlights his perceived "disconnect" between his experiences as a student learning proofs in prior courses and what he understands as a teacher to be good pedagogical practice:

There seems to exist a disconnect between the constructivist tenets and leanings of math education research and the traditional instruction of proof. Students are to make their own meaning of mathematics based on prior knowledge, yet when it comes to proof they are to conform to rigid conventions and opinions of elegance as defined by now dead white men.

As this quote highlights, John felt that PAR allowed him to actually learn by doing proofs, in a constructivist fashion. This was different from simply being expected to understand the "rigid conventions" of proofs constructed by someone else. John continues to contrast his experience with PAR and authentic engagement as pleasing, 
This diatribe, born from past frustrations, sheds some light on why I remain so pleased with my experiences with proof in this course (and in this school, really). I don't feel like the crazy person in the room for saying, "Copying it off the internet doesn't mean anything," and I'm no longer negatively reinforced for refusing to turn in "work" produced in this way. Proof has begun to feel personal - I feel as if I have some say in how I might structure certain problems or at least present my work. Additionally, the PAR process has completely changed the way I approach proofs and the way I teach. I feel as if the annotations column and its free form have given me a voice and choice in proof that didn't exist prior.

John describes his ownership over proof, how it has become something personal for him. Because he was able to engage in the process of proving, rather than just be given proofs as a thing to know, he developed his own knowledge in learning by doing. Rather than simply trying to achieve the right answer, proof become a practice that he authentically engaged with.

Dana similarly described how this course "opened her eyes" when it came to proof. Through working on PAR, she became to embrace the peer review process of annotating another student's work, and felt empowered that she could teach this process to her students. She remarked,

My experience in this class has opened my eyes to how to create and write a proof. Not only has this class taught me how to write a proof, but it has taught me how to read and analyze other people's proofs (which is a whole different monster). This is the first time I experiences the annotation process of a proof. Initially I found it annoying and did not understand the purpose of annotations... Overall, my experience with proof is constantly changing and I know it will change even more when I have to teach proof. I have not yet taught proof in the high school level, but I now feel that I am prepared to teach students how to write a proof.

Like John, Dana emphasized practices associated with proof, of reading and analyzing other's work. Again, learning by doing was a key aspect of coming to understand proof through PAR.

Finally, Melvin also described having a very different experience with this proof in the course. As with the other students, Melvin emphasized the process of proving, not just a proof as a thing to know,

Proofs in this class have been dramatically different from proofs in other math courses. Most proofs that I have worked with were used to serve on purpose and that was to show conjectures were true... This course was different in that I was pushed to think about proving things rather than the proof itself... The PAR process was a big part of the reason I looked at proofs differently in this course.

These responses illustrate how the extreme apprenticeship principle of learning by doing was a key part of how teachers engaged with the PAR process and how it influenced their perceptions of proof. Because teachers engaged with a structured practice (PAR), on a weekly basis, it became a part of their repertoire of what it meant to know and do mathematics.

\section{Continuous Feedback}

Extreme apprenticeship also emphasizes continuous, bi-directional feedback. While this is traditionally between a teacher and student, PAR offers an opportunity for students to provide bi-directional feedback to each other. In this way, students learn both from the process of giving and receiving feedback (Reinholz, 2015b). All three of the teachers in the course included in this study emphasized how this was a reflective process that allowed them to better clarify their own thinking.

John began by discussing how the opportunity to review and revise his work eliminated his fear of failure,

Having the opportunity to review a draft with a peer and then revise my work has taken the fear of failure out of the process. How does one fail a draft? The process also makes my own growth undeniable when I compare many of my drafts to their revised counterparts. 
As John describes, continuous feedback and revision turned working on the problems into a learning process, rather than just something that had to be done to achieve a grade. John goes further to describe how he has benefitted from the feedback of his peers,

While this is in part due to the spaced practice nature of the PAR process, it is also because of the feedback I receive from and provide to peers. Some of the best feedback has been in the form of questions: Is it legal to go from here to here? Can we assume this? Questions like these help me spot unsafe assumptions, or simply missed steps. Both push my learning.

Finally, John describes the other component of continuous feedback, in that he also learns from giving feedback,

I've also provided feedback about the structure of peers' proofs that helps me clarify my own thinking. For instance, I might struggle to follow the flow of a peer's work due to a muddled introduction/setup, and then recognize the same flaw in my own work (or at least identify areas where I could be more explicit).

This quote shows how giving feedback and recognizing the strengths and weaknesses of others' work allowed John to apply the same reflective lens to his own work. As John's quotes highlight, PAR gave him a mechanism to continually recalibrate his understanding, and more importantly, his understanding of his own understanding.

Dana also described the value of peer feedback, but for her it was important to connect to her work as an actual practicing teacher. Because she actually had to engage in the process of giving and receiving feedback as a student, she became more aware of important considerations for teaching her students,

Giving peer feedback on a proof is useful if done correctly. This is the first time I have ever given or received peer feedback. From this experience, I have learned what works best and important issues to remember when implementing this into my future lessons. I do give feedback to my students, however it would be nice to teach students how to give peer feedback. I think it is a good tool for students to learn how to annotate and critique work...I would make sure students felt comfortable giving feedback and learned how to be honest with their peers...Honest feedback is beneficial...[t]here are many reasons why one would feel uncomfortable to giving back honest feedback, so I can understand why students would hold back initially.

Here Dana is able to connect her authentic experience as a student to her work as a teacher. She highlights a key consideration - being able to give honest feedback - and how she needs to address it with her students.

Melvin focused his writing on the metacognitive aspect of peer feedback, through the annotation process. Melvin also draws attention to the dual processes of explicating his own thoughts and making sense of a peers' thoughts.

The annotations were focused on metacognition and the thought process about writing the proof. Having to write about my thought process and then reading someone's thought process helped me develop new ideas and new strategies to approach proofs... When reading a proof for annotation, it is important for the reader to make sure that anything that is not obvious to them is indicated. I believe that if the reader must ask for clarification then the reader should indicate that that part of the proof is not clear.

The process of explanation that Melvin describes is very different from writing a typical mathematics solution, in which the only audience is the teacher. Because the reader was an equal, he had to write his proofs in a different way, to support their understanding. In sum, these teachers were able to recognize the importance of continuous feedback in the PAR process and how it could influence them as students and teachers. 


\section{No Compromise}

The third principle, no compromise, was embodied into how students perceived proofs. In contrast to student perceptions of proof as empirical, the students had developed conceptions in line with the deductive logic of professional mathematicians. This is indicative of a high level of understanding and of a sophisticated way to think about proof.

John described the need to induce certainty in the audience. He elaborated that to do so, it must follow certain conventions (i.e. deductive logic) with supporting evidence,

$[B] y$ definition a proof is something that induces certainty in its audience. Leaving out necessary steps could stonewall this function...Inducing certainty in readers, however, requires an understanding of their possible perspectives. It is the author's purpose, then, to communicate the certainty of their claims by providing supporting evidence and connecting that evidence to their claims through valid reasoning. This communication is best achieved through an organized structure that allows the reader to expect certain conventions and thus anticipate possible paths.

As John describes a proof, he notes that there are both mathematical components (valid reasoning) and social components (possible perspectives). This shows his understanding that writing a proof does not just happen in vacuum, but is a social process. John goes on to elaborate what some of the mathematics components,

[A]ny good work will begin with definitions relevant to the given information or conjecture... in addition to definitions, the introduction and setup of a proof should include a clearly identified claim or conjecture that is to be proven or disproven... This section should intentionally answer the questions, "What are we about to prove?" and, "What do we need in order to accomplish this?" This is where the author familiarizes the reader with the tools that will be utilized to complete the proof (i.e. variables should be introduced and defined here, parameters should be set in this space, etc.).

This shift to focusing on definitions was a major epistemological shift for many of the students in the course, who still did not have a strong sense of exactly what was required for a proof to be valid.

Dana also describes the need to have an organized structure, and that "more than a picture" is required to actually have a proof,

A good proof should have an organized structure, contain the given and proof statement, and have selfannotations. In the very beginning of a proof, it is nice if the given is clearly stated along with the proof statement. Having a clear statement of what is given and what is being proved is helpful for the reader... It is not sufficient enough to prove something with just a picture or diagram.

Melvin also emphasized the importance of definitions and how to build logic on them. He also emphasized communication of helping someone "out of context" understand where things came from,

A good proof has multiple parts that make it understandable to someone who is reading it out of the context from the situation it was written in. A good proof is based on a definition and starts with some claim followed by a definition. A good proof highlights this definition and manipulates it to show the claim that is required to be true...Proofs should also make sense in terms of the "side work" that is required. Most textbook proofs have the major steps that help get to prove the claim but many of those steps seem to come from nowhere. Every line should lead to another line without any gaps in the logic of the proof. After this course, I believe that a good proof includes why the author of the proof did what he/she did.

Just like John, Melvin emphasizes aspects of proofs related to mathematical logic and social communication. In sum, the students were able to display a sophisticated understanding of a good proof, having no compromise on this quality of the work. It was a high standard that students worked hard to attain each week. 


\section{Apprentice to Mastery}

The final aspect of extreme apprenticeship is that the apprentice becomes a master. Here we can see this embodied in the teachers actually using PAR, the process they were using as students, as a teaching tool in their own classrooms.

John began talking about PAR on his first midterm. To frame his use of PAR, John discussed the concept of teacher clarity (Hattie et al., 2017). He said "As a new teacher I was heavily coached on making each lesson's learning intentions visible to my students through the use of daily 'Purpose' statements." John elaborated that students "needed a way of self-assessing whether or not they had achieved the purpose of the day." John discussed his struggles with this. "While I am pleased that success criteria are now available to students, I am not pleased with the proportion of students taking advantage of this tool." He then described how he was going to use PAR to address this issue,

Engaging in the PAR process has been an excellent learning experience. Self-assessing and providing feedback to peers are two areas that are far easier to promote than to implement. The PAR process, however, takes both of these elements and wraps them up into a pre-existing routine - homework. Because of this, I plan to use the PAR process (as modeled for us in class) to make success criteria more visible to students.

Here John was able to connect ideas from this course to a real problem of practice he was experiencing as a teacher. Later in the semester, John talked to me on multiple occasions about how he was using PAR with his students. In a final reflection on the second midterm he talked about his experiences,

I am proud to say that I can recognize a good thing when I see it, and that I have successfully transferred the experience to my students. I have always fostered a culture of collaboration in my classroom, but this PAR process facilitates the feedback component better than anything I've tried in the past.

John was enthusiastic about his use of PAR as a teacher in his own K-12 classroom. Similarly, Dana was able to use ideas from analysis with her high school students. She described,

I love the idea of how we use the PAR in our class. I have tried to incorporate this into my lesson plan because I think it is a wonderful idea for students to look at other students' solutions...I altered it slightly to make it work for high school students. We do a PAR every Friday...Friday PARDAY is what I call it.

Dana's enthusiasm was evident. She actually brought scanned work from her 9th grade class to share with our analysis class. When sharing that work with our class, she remarked, "initially I was skeptical that I would be able to use anything from this class in my own teaching, but it turns out that I have been able to."

While Melvin had not yet implemented PAR in his class, he had already made definite plans to do so in the coming year, as a part of another grant-funded project he was involved in. Melvin described his class as "entirely task based with little to no direct instruction." He discussed his plans "to use the PAR process in a course I will be teaching next year." He described his rationale,

Giving my students the opportunity to revise their work, gives them an opportunity to review their thought process. This gives them an advantage when it comes to assessments and the SBAC [Smarter Balanced Assessment Consortium] because they are required to justify their work and explain their thoughts. By doing the revisions, my students will gain the skills needed to know what mathematical advice is worthwhile and what advice does not help their cause, because not every annotation they get back is always going to be correct.

The SBAC was a standardized test Melvin had to prepare his students for. He also discussed the value of creating appropriate pairs, 
With the integrated courses, the students often run into problems where they can analyze the geometrical portions or they can solve the algebraic portions but not connect the two. If the ideal students are paired, they would make up for each other's lack of knowledge.

Melvin spoke with me about these plans after our class sessions, to receive further advice around implementation. In sum, these three teachers were already able to thoughtfully implement PAR in their teaching, or had laid out concrete plans to do so.

\section{Discussion}

Learning to teach is challenging, especially with few models for what one might achieve in their classroom. Thus, content courses are a key site for the learning of new teachers, because they can provide such models. More than providing content knowledge, when teachers have authentic learning experiences, they can draw upon them for their own teaching. This brief article highlights how three focal teachers were able to embody the four tenets of extreme apprenticeship and become masters, implementing PAR in their own teaching.

It is noteworthy that these teachers were never explicitly asked to use anything from the analysis class in their own teaching. Nor were they explicitly instructed on how connect the course with their own teaching. Rather, their insights were spontaneous. In many cases, the teachers were excited by the new content and methods that they were learning and they were eager to use them in their own practice. As such, this article highlights the importance of and potential for teachers' pedagogical learning in mathematics content courses.

The PAR cycle seemed particularly valuable for the teachers, as it gave them a clear model of a structured teaching technique that they could use. Although it was not the focus of this article, many of the teachers in the class described prior negative experiences with proof and how PAR opened up space for them to engage with proof differently (e.g., John's "diatribe born from past frustrations"). It is possible that teachers recognized their own struggles as mathematics learners, which allowed them to empathize with their students. When the teachers had a positive experience with PAR, they then worked to transfer that experience to their students.

While this article focused on just three of the five in-service teachers, other members of the course also connected with their experiences. For instance, the student in the course who was not in a mathematics education program wrote the following,

I never intended to be a teacher, but I must say I was inspired by this class to maybe think about it. It was so pleasant to be in a classroom full of teachers. In other classes, my classmates were never easy to approach and share information. It was the total opposite in this class. They were all just as supportive!

Although this is the reflection of just a single student, it adds evidence in support of the importance of math learning experiences for teachers.

Methods such as PAR and extreme apprenticeship can be used together to create authentic learning experiences for teachers in higher-level courses, which may ultimately impact the future practice of those teachers. Given that PAR has been used in a variety of STEM subjects, and extreme apprenticeship is also a cross-disciplinary framework, there is great potential for these results to also apply to other STEM disciplines. These frameworks help students learn by doing, which the results of this article suggest can be effectively implemented even in higher-level content courses. 


\section{References}

Averill, R., Drake, M., Anderson, D., \& Anthony, G. (2016). The use of questions within in-the-moment coaching in initial mathematics teacher education: enhancing participation, reflection, and co-construction in rehearsals of practice. Asia-Pacific Journal of Teacher Education, 1-18.

Black, P., Harrison, C., \& Lee, C. (2003). Assessment for learning: Putting it into practice. Berkshire, England: Open University Press.

Cobb, P., Stephan, M., McClain, K., \& Gravemeijer, K. (2011). Participating in classroom mathematical practices. A Journey in Mathematics Education Research, 117-163.

De Villiers, M. (2003). Rethinking proof with the geometer's sketchpad. Emeryville, CA: Key Curriculum Press.

Dewey, J. (1933). How we think: A restatement of the relation of reflective thinking to the educative process. New York, NY: D.C. Heath and Company.

Fischbein, E. (1982). Intuition and Proof. For the Learning of Mathematics, 3(2), 9-24.

Freeman, S., Eddy, S. L., McDonough, M., Smith, M. K., Okoroafor, N., Jordt, H., \& Wenderoth, M. P. (2014). Active learning increases student performance in science, engineering, and mathematics. Proceedings of the National Academy of Sciences, 201319030.

Hanna, G. (1990). Some pedagogical aspects of proof. Interchange, 21(1), 6-13.

Harel, G., \& Sowder, L. (2007). Toward comprehensive perspectives on the learning and teaching of proof. In F. Lester (Ed.), Second handbook of research on mathematics teaching and learning (pp. 805-842). Charlotte, NC: National Council of Teachers of Mathematics.

Hattie, J. A., Fisher, D., Frey, N., Gojak, L. M., Moore, S. D., \& Mellman, W. L. (2017). Visible learning for mathematics. Thousand Oaks, CA: Corwin.

Healy, L., \& Hoyles, C. (2000). A study of proof conceptions in algebra. Journal for Research in Mathematics Education, 31(4), 396-428.

Kolb, D. A. (1984). Experiential learning: Experience as the source of learning and development (Vol. 1). Upper Saddle River, NJ: Prentice-Hall.

Lave, J. (1996). Teaching as learning, in practice. Mind, Culture, \& Activity, 3(3), 149-164.

Martin, W. G., \& Harel, G. (1989). Proof frames of preservice elementary teachers. Journal for Research in Mathematics Education, 20(1), 41-51.

Mason, J., Burton, L., \& Stacey, K. (2010). Thinking mathematically (2nd ed.). Harlow, England: Pearson Education Limited.

Michaelsen, L. K., Parmelee, D., McMahon, K. K., \& Levine, R. E. (Eds.). (2008). Team-based learning in health professions education. Sterling, VA: Stylus Publishing.

Reinholz, D. L. (2015a). Peer-Assisted Reflection: A design-based intervention for improving success in calculus. International Journal of Research in Undergraduate Mathematics Education, 1(2), 234-267.

Reinholz, D. L. (2015b). The assessment cycle: A model for learning through peer assessment. Assessment \& Evaluation in Higher Education, 1-15.

Reinholz, D. L. (2016). Developing mathematical practices through reflection cycles. Mathematics Education Research Journal, 28(3), 441-455.

Reinholz, D. L. (2017). Not-so-critical friends: Graduate student instructors and peer feedback. The International Journal for the Scholarship of Teaching and Learning, 11(2), Article 10.

Reinholz, D. L., \& Dounas-Frazer, D. R. (2016). Using Peer Feedback to Promote Reflection on Open-Ended Problems. The Physics Teacher, 54(6), 364-368. 
Sfard, A. (1998). On two metaphors for learning and the dangers of choosing just one. Educational Researcher, $27(2), 4-13$.

Sherin, M., Jacobs, V., \& Philipp, R. (2011). Mathematics teacher noticing: Seeing through teachers' eyes. New York, NY: Routledge.

Steiner, M. (1978). Mathematical explanation. Philosophical Studies, 34(2), 135-151.

Vihavainen, A., Paksula, M., \& Luukkainen, M. (2011). Extreme Apprenticeship Method in Teaching Programming for Beginners. In Proceedings of the 42Nd ACM Technical Symposium on Computer Science Education (pp. 93-98). New York, NY, USA: ACM.

\section{Appendix. Sample PAR work}

\section{The PAR Process}

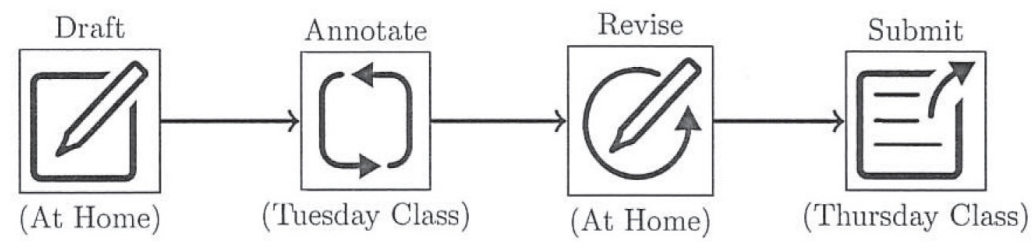

Write your solution in the left column. The right column is used for annotations. If you provide feedback to your peer, you will annotate their solution. After class, you will annotate your own solution as well (and write "self" on the annotated by line). In your submission, use the annotation column to explain how you did (or didn't) response to peer feedback.

\section{Problem Statement: Continuity}

There are a number of different ways to define continuity, starting from the definition you are familiar with for real numbers, to other definitions that can work in more abstract metric spaces. Here are two of them:

1. A function $f$ is continuous at a point $c$ in its domain if for every $\varepsilon>0$ there exists a $\delta>0$ so that for all $x$ with $|x-c|<\delta,|f(x)-f(c)|<\varepsilon$.

2. A function $f$ is continuous at a point $c$ in its domain if for any neighborhood $N_{1}(f(c))$ there is neighborhood $N_{2}(c)$ such that $f(x) \in N_{1}(f(c))$ whenever $x \in N_{2}(c)$

Your goal is create two functions, the happy function and the sad function.

1. For the happy function, find a point $c$ at which it is continuous, and prove that it is continuous using both of these definitions.

2. For the sad function, find a point $c$ at which it is not continuous, and prove that it is not continuous using both of these definitions. 


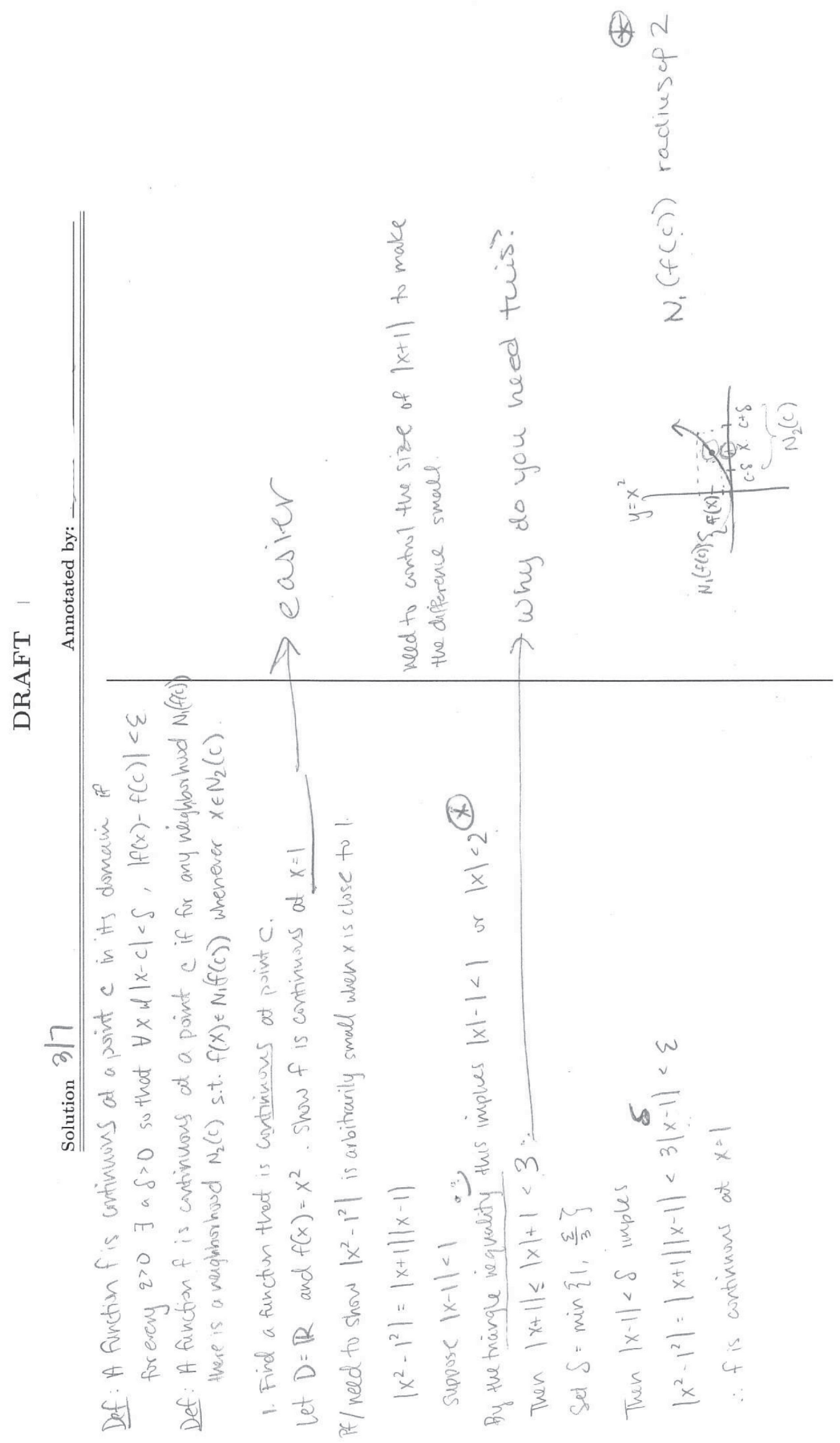




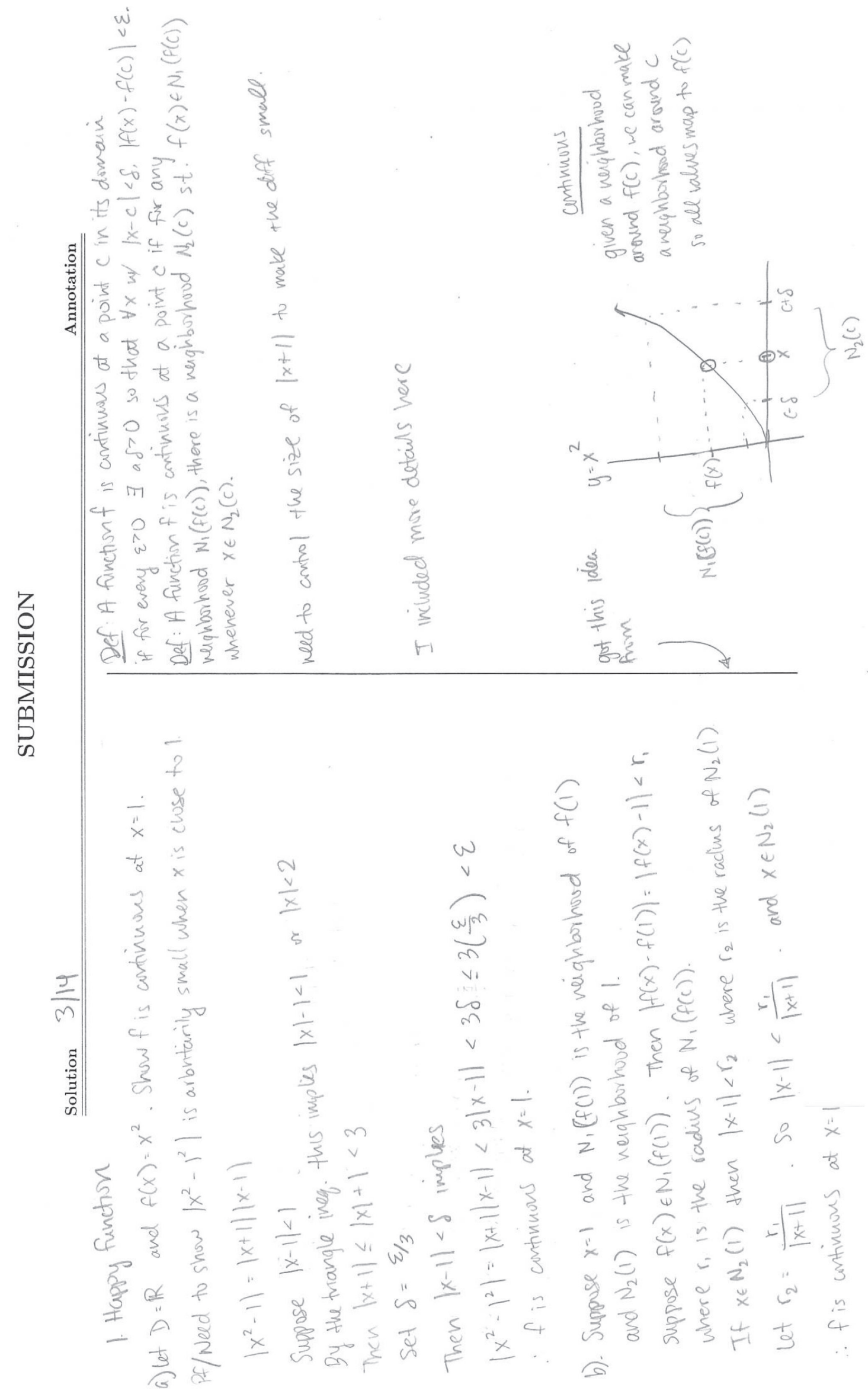

